\title{
EFFICACY OF ANTIFUNGAL TREATMENT IN THE CLINICOMYCOLOGICAL CURE OF T. CORPORIS/T. CRURIS
}

\author{
Sajitha K1, Carol Z. Fernandes ${ }^{2}$
}

${ }^{1}$ Associate Professor, Department of Microbiology, Dr. B. R. Ambedkar Medical College, KG Halli

${ }^{2}$ HOD, Department of Dermatology, Bangalore Baptist Hospital, Hebbal, Bengaluru.

\section{ABSTRACT}

\section{BACKGROUND}

Dermatophytes are among the common fungal agents causing superficial skin infections worldwide. They affect about $20-25 \%$ of the world population and the causative agents of these infections vary from place to place. The present study was aimed at finding out the clinicomycological pattern of dermatophytosis, aetiological agents, comparing the clinical diagnosis with laboratory investigations and the clinicomycological cure following treatment. Terbinafine is well tolerated on topical administration and has low potential for drug interactions. In clinical trials, mycological and overall efficacy rate of topical terbinafine is around $80 \%$ and with an intermittent pulse dose therapy, cure rate of around $90 \%$ has been reported.

\section{MATERIALS AND METHODS}

This was a case series study of 50 patients. Clinical specimens like skin scraping were collected under aseptic precautions and sent to laboratory. All specimens were subjected to direct microscopy for fungal elements in $10 \% \mathrm{KOH}$ and only KOH positive cases were included in the study. Culture was done in Sabouraud's dextrose agar with chloramphenicol and cycloheximide and incubated at $26^{\circ} \mathrm{C}$ and $37^{\circ} \mathrm{C}$ separately. The colony morphology was identified by microscopy and confirmation of morphology was done by slide culture. All patients were treated with 1\% topical terbinafine cream, twice daily for 4 weeks. KOH mount was repeated posttreatment and those patients who were not clinically and mycologically cured were treated with oral terbinafine for two weeks and topical terbinafine for another 4 weeks.

\section{RESULTS}

Out of 50 patients, maximum were seen in the age group of 18-27 years (32\%). All 50 samples were positive by microscopic examination, out of which $48 \%$ were positive by culture. Trichophyton rubrum $(54.16 \%)$ was the commonest isolate followed by $\mathrm{T}$. mentagrophytes (33.33\%), M. gypseum (4.16\%) and M. audouinii (4.16\%). 90\% of patients had clinical cure (absence of visible erythema and scaling) after treatment with topical terbinafine for 4 weeks. The remaining patients were treated with oral terbinafine for two weeks and topical cream for another 4 weeks. During follow-up after 8 weeks, KOH mount was negative for all patients except one patient who was $\mathrm{KOH}$ and culture positive with same fungal isolate.

\section{CONCLUSION}

This study highlights a common problem in many areas of the world and suggests that further measures regarding public health and personal hygiene must be undertaken in order to reduce the risk of dermatophytosis. Also, a short duration of topical terbinafine along with systemic terbinafine, if required is very effective in the treatment of T. corporis/T. cruris. The endpoint of treatment is the clinical and mycological resolution.

\section{KEYWORDS}

Superficial Fungal Infection, Dermatophytes, Tinea, Trichophyton Rubrum, Terbinafine Hydrochloride.

HOW TO CITE THIS ARTICLE: Sajitha $\mathrm{K}^{1}$, Fernandes CZ. Efficacy of antifungal treatment in the clinicomycological cure of T. corporis/T. cruris. J. Evolution Med. Dent. Sci. 2017;6(66):4765-4768, DOI: 10.14260/Jemds/2017/1032

\section{BACKGROUND}

Dermatophytes are among the common fungal agents causing superficial skin infections worldwide. They are keratophilic, hence colonise keratinised tissue (stratum corneum of epidermis, hair \& nail) and induce an inflammatory response.1,2 Trichophyton, Microsporum, Epidermophyton are three genera of dermatophytes implicated in superficial mycosis. ${ }^{3}$ Based on habitat (Source of the keratin used), they are classified as Geophilic (Organism originates from soil),

Financial or Other, Competing Interest: None.

Submission 21-06-2017, Peer Review 07-08-2017,

Acceptance 12-08-2017, Published 17-08-2017.

Corresponding Author:

Dr. Sajitha K,

No. 5, Manuvana, $1^{\text {st }}$ Main,

D Cross, Vijayanagar, Bangalore-560040.

E-mail: sajithakarunan@gmail.com

DOI: $10.14260 /$ jemds $/ 2017 / 1032$
Anthropophilic (organism originates from humans), Zoophilic (Organism originates from animals). ${ }^{2}$ Dermatophytosis is more prevalent in tropics, and may reach epidemic proportions in areas where high rate of humidity, overpopulation and poor hygienic conditions are prevalent. ${ }^{4}$

Dermatophytosis has been classified, according to the site of infection. ${ }^{5}$

- Tinea capitis - affects the scalp and hair.

- Tinea faciei - affects the face.

- Tinea barbae - affects facial hair in adult males.

- Tinea corporis - affects the glabrous skin.

- Tinea cruris (jock itch) - affects the groins.

- Tinea manuum - affects the palmar area.

- Tinea pedis (athlete's foot) - affects the feet.

- Tinea unguium - affects the finger nails and toe nails. 
India is a large subcontinent with remarkably varied topography, situated within the tropical and subtropical belts of the world. Its climate is conducive to the acquisition and maintenance of mycotic infections. Although common, the precise size of the problem defies measurement. ${ }^{4}$

\section{Aim of the Study}

The present study was undertaken to:

1. Investigate the clinical pattern of dermatophytosis of the glabrous skin and groin.

2. Identify the species of fungi.

3. Compare the clinical diagnosis with $\mathrm{KOH}$ positivity and culture positivity.

4. Analyse the clinicomycological cure following oral and topical treatment with terbinafine.

\section{MATERIALS AND METHODS}

This was a case series study which included 50 patients, over three months diagnosed clinically as having dermatophytosis who were randomly selected from the Dermatology OPD, Dr. B. R. Ambedkar Medical College Hospital, Bangalore. A detailed history was taken from all patients, which included age, sex, occupation, socioeconomic status, duration of disease, history of recurrence, habits and associated diseases. History of similar illness in family members and contact with animals or soil was also obtained. A wash out period of 15 days was advised for all patients applying any medication. Thus, patients with Tinea incognito were not included. Also, patients with serious systemic underlying conditions and other infections like bacterial and fungal infections (like candidiasis and pityriasis) were excluded.

The lesion was assessed using the investigator's static global assessment score which included scaling, erythema and pruritus and size of the lesion less than $30 \%$ of body surface area being involved. Skin scrapings were collected from the active edge of the lesions under aseptic precautions.

Direct microscopy (in 10\% $\mathrm{KOH}$ ), mounted on a glass slide was done under microscope for the presence of fungal elements and culture was done in each case. For isolation, Sabouraud's dextrose agar with chloramphenicol and cycloheximide prepared in our department were used and incubated at $26^{\circ} \mathrm{C}$ and at $37^{\circ} \mathrm{C}$ for a period of 4 weeks. Colony of each isolate was stained with Lactophenol cotton blue (LPCB) and observed under microscope. The identification was based on colony morphology and LPCB mount on features like microconidia, macroconidia and additional structures. Confirmation of isolate was done by slide culture.

\section{RESULTS}

Out of the 50 patients, the maximum were seen in the age group 18 to 27 years (32\%). Most patients belonged to the $3^{\text {rd }}$ decade of life. The youngest patient was an 18-year-old boy and the oldest a 65-year-old man. Male to female ratio was 1.6:1 (Figure 1). Majority of the patients belonged to the lower income group.

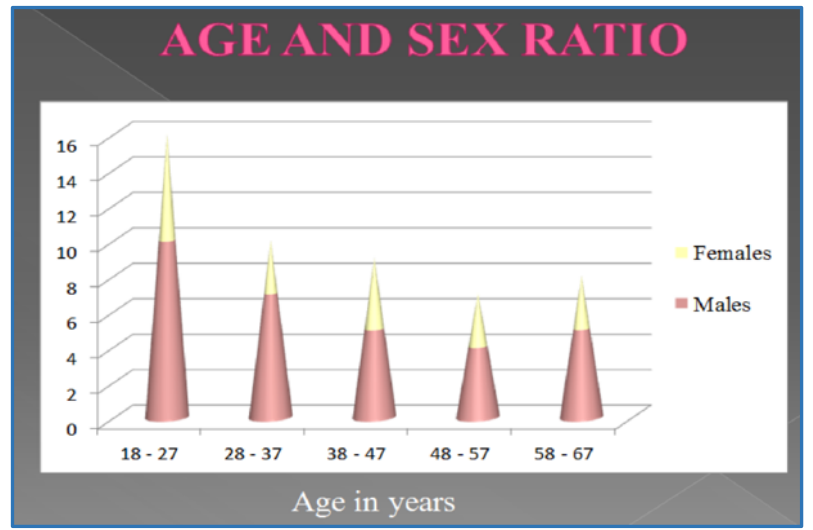

Figure 1. Age and Sex Distribution of Patients

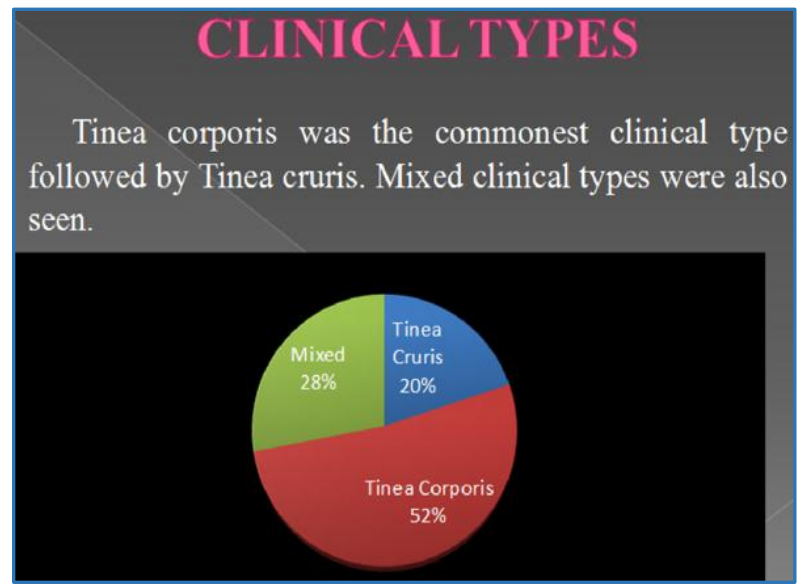

Figure 2. Distribution of Clinical types of Fungal Infections

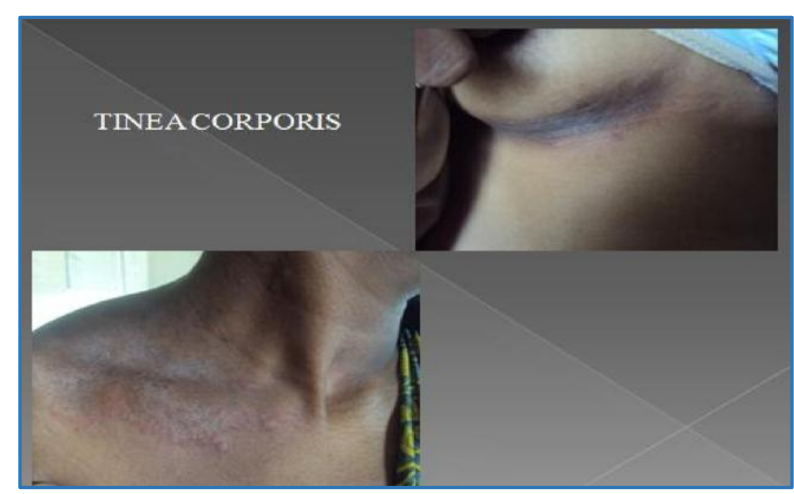

Figure 3. Cases of Tinea corporis

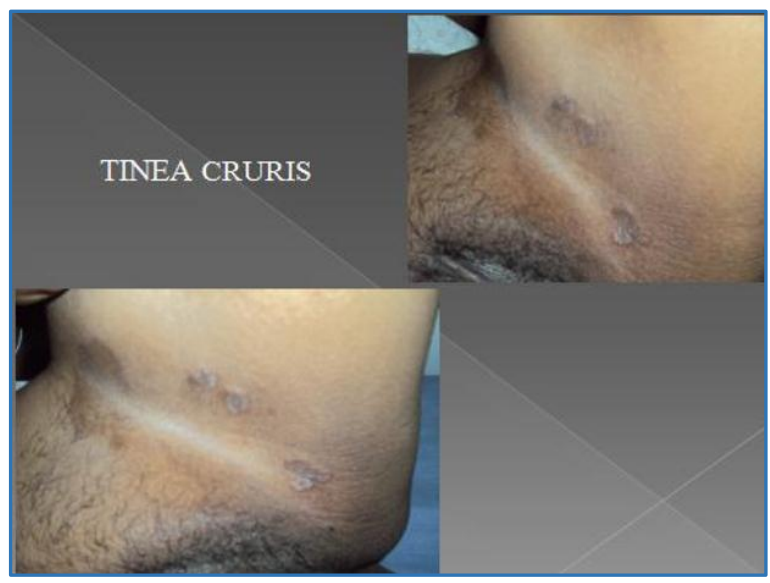

Figure 4. Cases of Tinea cruris 


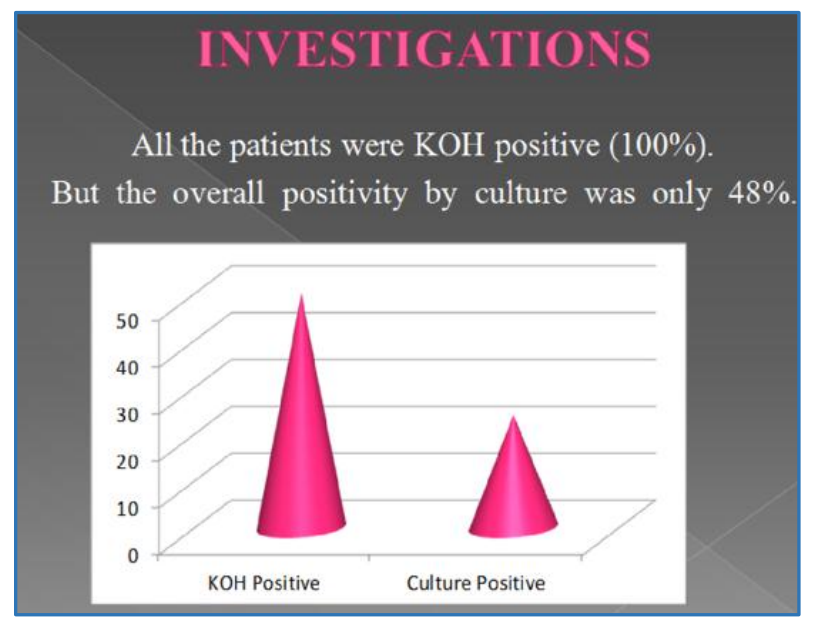

Figure 5. Details of Investigations (KOH Mount and Culture Positivity)

\section{Species Isolated}

Trichophyton rubrum was the predominant species isolated $(54.16 \%)$ followed by T. mentagrophytes (33.33\%). Other isolates included Microsporum nanum, Microsporum gypseum and Microsporum audouinii (4.16\% each) (Figure-6, 7,8).

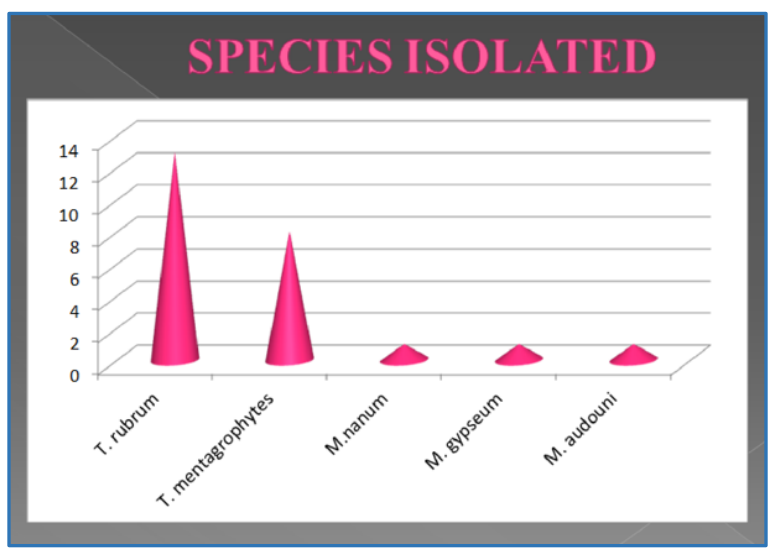

Figure 6. Breakup of Species Isolated

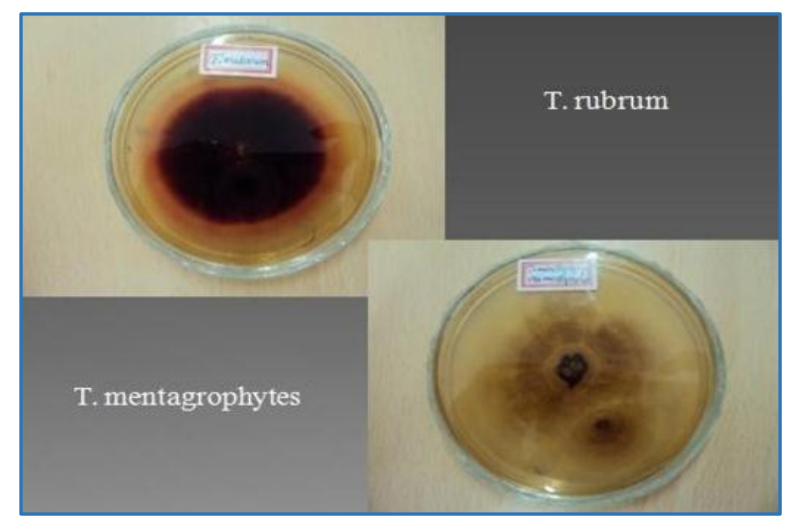

Figure 7. Isolates of Trichophyton spp.

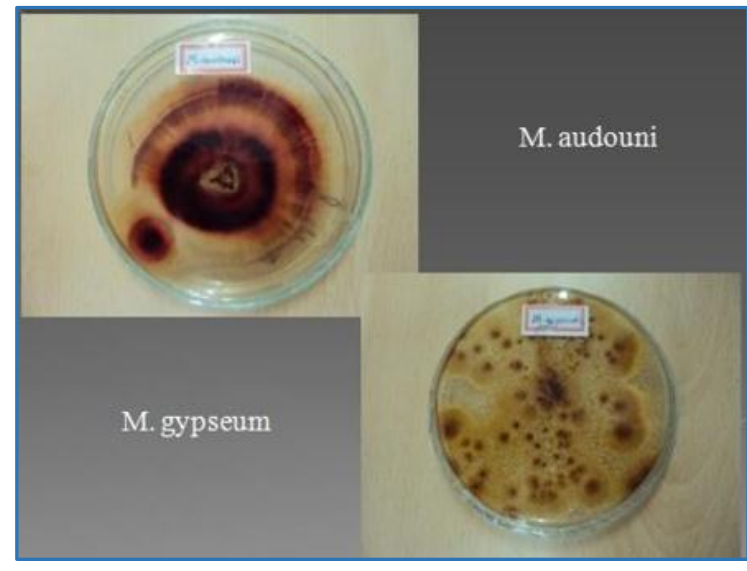

Figure 8. Isolates of Microsporum spp.

\section{Treatment}

Since all the patients had body surface involvement of around $30 \%$ they were started on topical terbinafine cream, twice daily for 4 weeks. All the patients showed clinical improvement.

\section{Post Treatment}

$\mathrm{KOH}$ mounts were repeated post-treatment, 90\% (45) patients recovered both clinically and mycologically. Out of the remaining $10 \%(05)$ patients, 4 patients with mixed infections and one patient with $\mathrm{T}$. corporis were treated with oral Terbinafine $250 \mathrm{mg}$ once daily for two weeks and topical cream for another 4 weeks. There was complete cure in all patients by the end of 8 weeks, except one patient, who was still culture positive post-treatment and the same fungal isolate T. mentagrophytes var. mentagrophytes was isolated.

\section{DISCUSSION}

In the present study, maximum number of patients were seen in the third decade with males outnumbering females, as compared to other studies.6,7,8 The higher incidence in young males could be due to greater physical activity and increased sweating.5,9 The commonest clinical types of dermatophytosis was Tinea corporis followed by Tinea cruris as the symptoms makes the patient to seek medical advice. Similar findings have been reported by other workers, both in India and abroad. $7,9,10,11$

All our patients were positive on direct microscopy. However, only $48 \%$ specimens were positive by culture. T. rubrum, an obligate anthropophilic dermatophyte was the most common isolate (54.16), almost equally isolated from $\mathrm{T}$. corporis (4), T. cruris (5) and mixed infections (4) followed by T. mentagrophytes (33.33\%), isolated from T. corporis (3), T. cruris (1) and mixed (4). This is in keeping with other Indian and western studies.9,12,13 Trichophyton mentagrophytes also has a major reservoir in rodents. One of our patient from whom T. mentagrophytes var. mentagrophytes, a zoophilic species isolated was a temple priest. This patient showed recurrence of lesions and his culture post treatment also isolated the same species. He had controlled diabetes mellitus. Probably he was exposed to the rodents in the temple, repeatedly. In a study at Madras, all patients were diabetic but our patient had controlled diabetes mellitus. ${ }^{14}$ Hay has reported that diabetes is a predisposing factor in the development of dermatophytosis. ${ }^{3}$ One more interesting zoophilic species isolated was $M$. nanum from a case of T. corporis similar to a study at Madras, as this patient had been to his village where pigs were 
present. ${ }^{15}$ The most common geophilic species, M. gypseum was isolated from a case of T. corporis who came with high inflammatory reaction on his hand. ${ }^{4,16} \mathrm{M}$. audouinii was isolated from a case of T. corporis in an 18-year-old male patient similar to a study from North India. ${ }^{17}$ It is commonly isolated from T. capitis in children, but we isolated from an adult male, probably he was in contact with children while playing. ${ }^{18,19}$ This highlights the importance of both direct microscopy and culture in the definitive diagnosis and prevention of recurrence of dermatophytosis.

\section{Treatment}

The treatment is based on the site of infection, aetiological agents and the ability of the drug to act at that site. Though topical antifungals are sufficient for the cure of Tinea corporis/Tinea cruris for a short duration, some lesions fail to respond to topical therapy and need oral therapy. ${ }^{20}$ Earlier days Griseofulvin was the drug of choice for tinea infections, but gradually the relapse rate increased and thus Terbinafine was pushed to the forefront for the treatment of Tinea corporis/Tinea cruris. ${ }^{21}$ Terbinafine is well tolerated after topical or oral administration and has a relatively low potential for drug interactions. Pharmacoeconomic data support the use of terbinafine in dermatophyte infections of the skin and nails. ${ }^{22}$ As the body surface involvement was around $30 \%$, patients were started on topical $1 \%$ Terbinafine hydrochloride cream twice daily for 4 weeks, $90 \%$ of patients recovered, remaining $10 \%$ of patients were treated with oral Terbinafine for 2 weeks and topical terbinafine for another 4 weeks. There was complete cure in all patients by 8 weeks except for one patient with T. corporis, who was repeatedly in contact with rodents indirectly. In an update of use of terbinafine in superficial mycoses, the use of $1 \%$ terbinafine hydrochloride cream in T. corporis/T. cruris showed that in more than $80 \%$ of patients there was complete cure rate, ${ }^{22}$ but in our study the cure rate was $90 \%$ at the end of 4 weeks and $98 \%$ of all patients with complete cure at the end of 8 weeks. All our patients were followed up till the end of 8 weeks with complete cure and the drug showed good tolerability with no adverse effects, also a short duration of oral terbinafine is very effective in extensive cases of T. corporis/T. cruris. ${ }^{22}$ Thus, the efficacy of the drug to $\mathrm{T}$. corporis and T. cruris was very good both topically and systemically and complete cure can be obtained by 4-8 weeks.

\section{CONCLUSION}

This study highlights a common problem in many areas of the world and suggests that further measures regarding public health and personal hygiene must be undertaken in order to reduce the risk of dermatophytosis. Also, a short duration of topical terbinafine along with systemic terbinafine, if required is very effective in the treatment of T. corporis/T. cruris. The endpoint of treatment is the clinical and mycological resolution.

\section{REFERENCES}

[1] Emmons CW, Binford CH, Litz JP, et al. Medical mycology. $3^{\text {rd }}$ edn. Lea and Febiger, Philadelphia 1977:117-67.

[2] Chander J. Dermatophytoses. In: Textbook of medical mycology. 2nd edn. New Delhi: Mehta Publishers 2002:91-112.
[3] Hay RJ. Cutaneous and subcutaneous mycosis. In: Anaissie EJ, McGinnis MR, Pfaller MA. (eds). Clinical mycology. $1^{\text {st }}$ edn. Philadelphia: Churchill Livingstone 2003:456-60.

[4] Patwardhan N, Dave R. Dermatomycosis in and around Aurangabad. Ind $\mathrm{J}$ Pathol Microbiol 1999;42(4):455-62.

[5] Weitzman I, Summerbell RC. The dermatophytes. Clin Microbiol Rev 1995;8(2):240-59.

[6] Prasad P, Shivananda PG, Srinivas CR, et al. Indian J Dermatol Venereal Leprol 1987;53:217-8.

[7] Amma SM, Paniker CK, Gopinathan T. Studies on dermatomycoses in Calicut (Kerala). Clinical and mycological investigations. Indian J Pathol Microbial 1982;25(1):11-7.

[8] Bhargovi L. Study on the aetiologies of dermatophytosis in Calicut. Thesis for MD (Microbiology), University of Calicut 1979.

[9] Belukar DD, Bharmal RN, Kartikeyan S, et al. A mycological study of dermatophytoses in thane. Bombay Hospital Journal 2004;46:1-4.

[10] Huda MM, Chakraborty N, Bordoloi JNS. A clinicomycological study of superficial mycoses in upper Assam. Indian J Dermatol Venereal Leprol 1995;61(6):329-32.

[11] Kamalam A, Thambiah AS. A study of 3891 cases of mycoses in the tropics. Sabouraudia 1976;14(2):12948.

[12] Raja SM, Menon T. Clinicomicrobiological aspects of tinea cruris in Madras. Ind J Dermatol Venereol Leprol 1994;62:210-12.

[13] Singh S, Beena PM. Profile of dermatophyte infections in Baroda. Ind J Dermatol Venereol Leprol 2003;69(4):281-3.

[14] Partiban K, Janaki C, Selvi GS, et al. Dermatomycoses in diabetics-a clinical study. Ind J Dermatol 1988;43(2):50-2.

[15] Ranganathan S, Menon T, Balajee SA. Isolation of Microsporum nanum from a patient with tinea corporis in Madras, India. Mycoses 1997;40(5-6):22930.

[16] Pankajalakshmi VV, Subramanian S. Mycoses in Madras (superficial). Ind J of Dermatol and Venereol 1974;40:228-35.

[17] Malik AK, Chugh TD, Prakash K. Dermatophytosis in North India. Ind J Pathol Microbiol 1978;21(1):53-9.

[18] Hernandez AD. An approach to the diagnosis and therapy of dermatophytosis. Indian J Dermatol Venereal Leprol 1987;53:174-5.

[19] Kumar AG, Lakshmi N. Tinea capitis in Tirupati. Ind J Pathol Microbiol 1990;33(4):360-3.

[20] Rand S. Overview: the treatment of dermatophytosis. J Am Acad Dermatol 2000;43(5 Suppl):S104-12.

[21] Voravutinon V. Oral treatment of tinea corporis and tinea cruris with terbinafine and griseofulvin: a randomized double blind comparative study. J Med Assoc Thai 1993;76(7):388-93.

[22] McClellan KJ, Wiseman LR, Markham A. Terbinafine. An update of its use in superficial mycoses. Drugs 1999;58(1);179-202. 